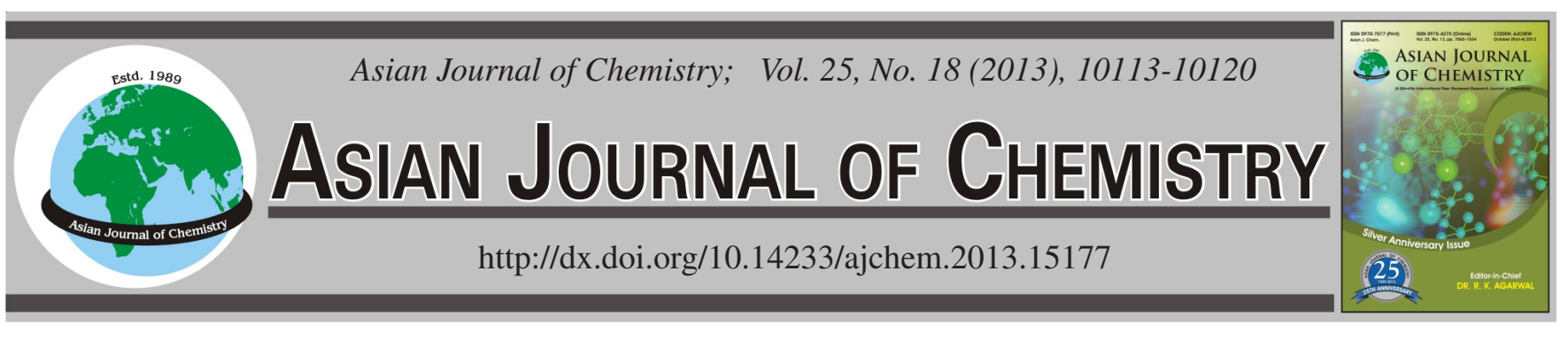

\title{
Performance of Treating Synthetic High-Strength Wastewater by Hybrid Vertical-Subsurface Flow Constructed Wetlands in Response to Various Two-Stage Combinations of Vertical Up-Flow and Down-Flow
}

\author{
F. ZHANG ${ }^{1}$, P. CHENG ${ }^{2}$, Y.J. ZHAO ${ }^{3, *}$, C. YAN ${ }^{3}$ and C.W. Hu ${ }^{4, *}$
}

${ }^{1}$ School of Food and Bioengineering, Zhengzhou University of Light Industry, Zhengzhou 450002, P.R. China
${ }^{2}$ Department of Animal Husbandry Engineering, Zhengzhou College of Animal Husbandry Engineering, Zhengzhou 450011, P.R. China
${ }^{3}$ College of Biological, Chemical Science and Engineering, Jiaxing University, Jiaxing 314001, P.R. China
${ }^{4}$ Shandong Provincial Key Laboratory of Water and Soil Conservation \& Environmental Protection, Linyi University, Linyi 276005, P.R. China

*Corresponding author: Tel/Fax: +86 539 8766307; +86 573 83647467; E-mail: changwei.hu@163.com; zyjun2007@163.com

\begin{abstract}
The performance and temporal variation of hybrid vertical-subsurface flow constructed wetlands (VFCWs) in response to two-stage combinations of vertical up-flow (VUF) and vertical down-flow (VDF) were tested in order to treat non-point sources of pollution wastewater. The effect and seasonal variation of four kinds of two-stage combinations VFCWs (VUF-VUF, VDF-VDF, VUF-VDF and VDF-VUF) were analyzed by synthetic high organic/N loading wastewater. Furthermore, the impact of loading variation treatments, combination patterns, season variation and their interaction on treatment performance were calculated. Four kinds of two-stage combinations VFCWs all showed high nutrient removal efficiencies under high organic/N loading treatments and the optimum two-stage combination was VDF-VUF VFCWs. During the experimental period, the relatively higher nutrient removal efficiency was achieved in late summer (July and August) and early autumn (September) and the highest value was obtained in August. Chemical oxygen demand and total nitrogen removal efficiencies under high organic/N loading treatments were only significantly affected $(p<0.05)$ by season, system variation and the combined effect of season and system variation, while the total phosphorus removal efficiencies were not significantly affected $(p>0.05)$ by any factors.
\end{abstract}

Key Words: High organic/N loading, Seasonal variation, COD removal, Total nitrogen removal, Total phosphorus removal.

\section{INTRODUCTION}

Nowadays the non-point source pollution has been deemed the primary cause of eutrophication in fresh water sources ${ }^{1}$. For example, in Quebec, Canada, the increasing number of blue-green algae outbreaks in lakes and streams has been attributed to excess phosphorous in the watersheds with of $70 \%$ estimated to be coming from agricultural nonpoint sources ${ }^{2}$. However, the constructed wetlands (CWs) are considered as a promising technology to treat non-point sources of pollution wastewater ${ }^{3-6}$. For instance, Díaz et al. ${ }^{7}$ reported that the nitrate removal efficiencies of non-point source pollution from agricultural runoff in CWs was as high as $98 \%$; the phosphorus removal was approximately $80 \%$; while pesticides removal ranged from 0 to $100 \%$. The singlestage CWs mainly include horizontal-flow (HF) and verticalflow (VF) CWs. HF CWs cannot achieve fully nitried effluents due to their limited oxygen transfer capacity. VF CWs possess great oxygen transport ability to achieve a satisfactory level of nitrification but no denitrification ${ }^{8-10}$. Specially, wastewaters with high organic or $\mathrm{N}$ loading are difficult to treat in the singlestage CWs because of their inability to provide aerobic and anaerobic environments simultaneously ${ }^{11}$.

The hybrid CWs consist of various types of CWs can be a great potential ${ }^{12,13}$. The most common two-stage combinations CWs is the combination of VF and HF CWs. The VF-HF CWs derived from single-stage CWs exhibit a high COD removal efficiency. Furthermore, much higher TN removal efficiency was achieved compared to the single-stage HF CWs. This is because in the two-stage combinations VF-HF CWs, high nitrification was obtained in the VF section and nitrate produced in the VF section is successfully reduced in the subsequent HF section ${ }^{8,10,14}$. But when it comes to the phosphorus removal, efficiency of VF-HF CWs is still low $^{15-17}$. On the other hand, the HF-VF CWs represent a very low TN removal efficiency although the organics removal effect is very impressive. This is due to the relatively low denitrification in the last VF stage ${ }^{18}$. In fact, a lot of combinations of CWs are possible to achieve a relatively high $\mathrm{COD}, \mathrm{TN}$ and $\mathrm{TP}$ removal efficiency simulta- 
neously ${ }^{13}$. The potential combinations of CWs are including VF-VF CWs, HF followed by a free water surface wetland and by adding others stages of filters, $e$. $g$., water recirculation from one stage to another ${ }^{9,11}$. Variation of combinations of CWs have significant effects on the nutrient removal effect of wastewater $^{11}$. Therefore, identifying the optimum two-stage combinations CWs for efficient nutrient removal has great practical significance. Moreover, the selection of component of two-stage CWs is very important to its performance ${ }^{19}$. The single-stage vertical-subsurface flow constructed wetlands (VFCWs) are attracting more and more attention due to their excellent oxygen transfer capacity and steadily high nutrient removal efficiency under various months ${ }^{20,21}$. In fact, two kinds of the most frequent VFCWs, i.e., vertical up-flow (VUF) and vertical down-flow (VDF) CWs, are able to provide both aerobic and anaerobic conditions at the same time. Consequently, twostage combinations of VUF and VDF are promising CWs for nitrification, denitrification and COD and TP removal. Nevertheless, although there were a lot literatures demonstrating the potential of CWs to mitigate several non-point source pollutants ${ }^{1,7}$, the literature about the performance and advantages of this two-stage combination CWs are still rarely known.

In order to cover the shortages mentioned above, this research focuses on the performance and temporal variation of hybrid VFCWs in response to two-stage combinations of VUF and VDF. Furthermore, the impact of loading variation treatments, combination patterns, season variation and their interaction on treatment performance were investigated by synthetic high organic/N loading wastewater.

\section{EXPERIMENTAL}

Hybrid VFCWs: A set of hybrid VFCWs treatment included parallel four types of two-stage combinations of cascaded VUF and VDF CWs: VUF-VUF (CW1-CW2), VDFVDF (CW3-CW4), VUF-VDF (CW5-CW6) and VDF-VUF (CW7-CW8) (Fig. 1a). The set of hybrid VFCWs treatment was in octuplicate, each 4 sets of them were for high COD loading or high $\mathrm{N}$ loading. Then total 64 single-stage CWs (VUF or VDF) were established on the same conditions showed in Fig. 1b. Each single-stage VUF or VDF tank was $100 \mathrm{~cm}$ long $\times 60 \mathrm{~cm}$ wide $\times 90 \mathrm{~cm}$ high concrete tank (Fig. 1a) and established with a two-layer filter: $20 \mathrm{~cm}$ gravel (nominal mean diameter of particles was $1.45 \mathrm{~cm}$ ) in the bottom followed by $25 \mathrm{~cm}$ slag (nominal mean particle diameter was $1.75 \mathrm{~cm}$ ) at the top (Fig. 1b). The slag was cleaned more than six times in order to avoid creation of highly alkaline (high $\mathrm{pH}$ ) conditions that may be unfavorable for the development of plants and microorganisms. The sample connections were S1, S2, S3 and S4 (Fig. 1a).

Procedure: The hybrid VFCWs were located in a greenhouse in Zhengzhou, P.R. China, 3444'36"N 113³8'15"E. All wetlands were planted with Herba Scirpi Tabernaemontani $(15.37 \pm 2.15 \mathrm{~cm}$ tall), using 10 stems for per single-stage CWs (Fig. 1b) on the 1st of March 2011. Before introduction of influent wastewater, all set of hybrid VFCWs treatments were flooded for one month with tap water (1st of March 2011 to 31 st of March 2011). After that, the formal experiment was conducted between 1st of April 2011 and 31st of January 2012. The wastewater was introduced onto the surface of each type of two-stage combination treatment under flow rate $40 \mathrm{~L} \mathrm{~d}^{-1}$ through a round PVC pipe (5 $\mathrm{cm}$ internal diameter) which was placed on one side of the wetland surface. The pipe was equipped with holes of $2.5 \mathrm{~mm}$ placed at equal distances in order to distribute the wastewater evenly. Then, batch volumes of $200 \mathrm{~L}$ were applied weekly to each treatment by gravity for $5 \mathrm{~d}$ with the other $2 \mathrm{~d}$ remaining as dormant periods. The environmental conditions in different months during the formal experimental period (1st of April 2011 and 31st of January 2012) were recorded in Table-1.

Synthetic high-strength wastewater: For health and safety reasons, as well as for comparison of the parallel experiments, synthetic wastewater was used as the source of high-strength wastewater, simulating high COD loading or high $\mathrm{N}$ loading wastewater. The synthetic wastewater applied in

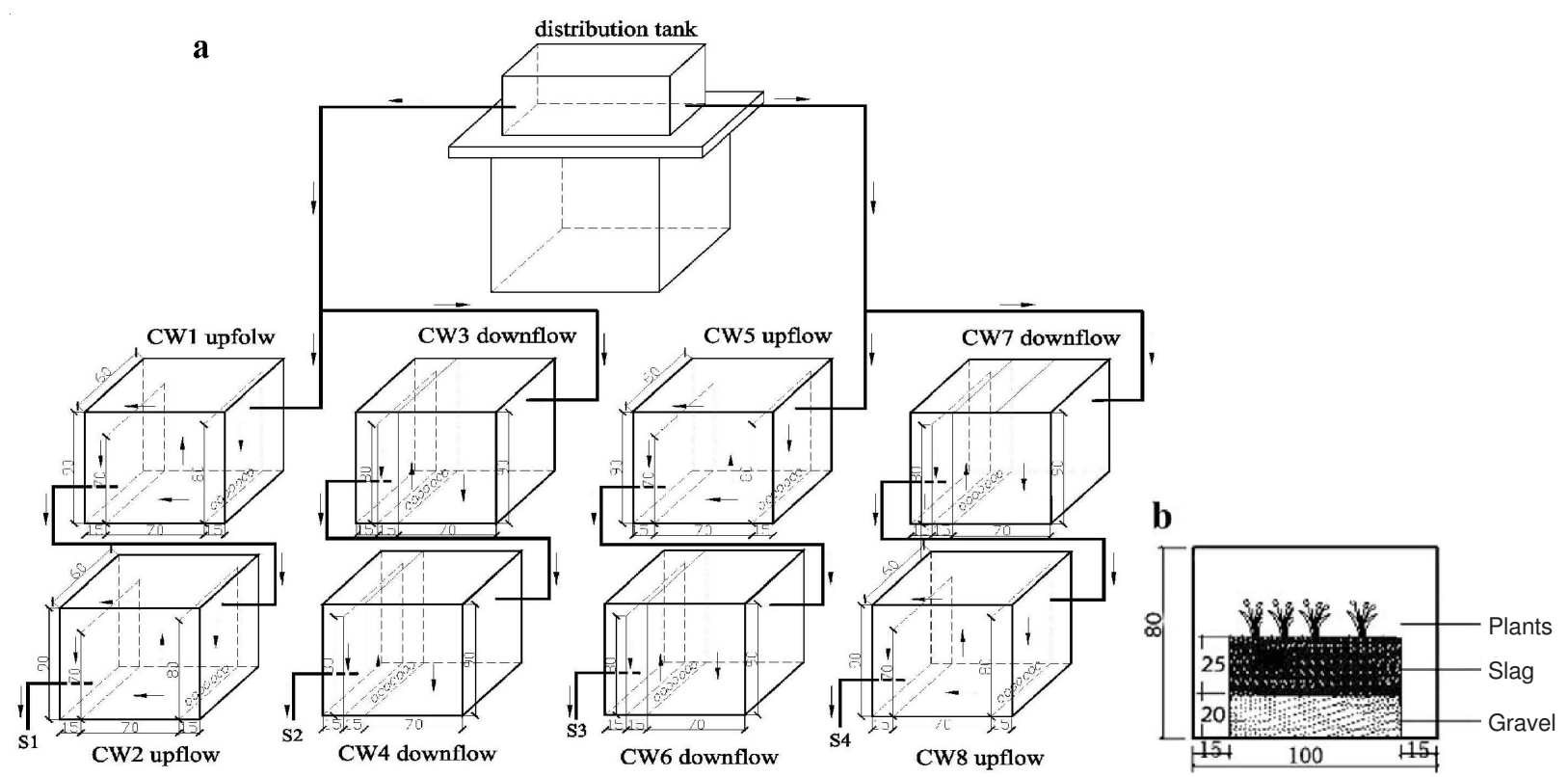

Fig. 1. Schematic diagram of wetlands: (a) a set of hybrid VFCWs treatment; (b) single-stage wetland construction (dimensions are in $\mathrm{cm}$ ) 


\begin{tabular}{cccccccccccc}
\hline \multicolumn{10}{c}{ TABLE-1 } \\
\multicolumn{10}{c}{ ENVIRONMENTAL CONDITION IN DIFFERENT MONTHS. (T - AVERAGE } \\
& \multicolumn{1}{c}{ TEMPERATURE, RH - RELATIVE HUMIDITY, WS - AVERAGE WIND SPEED) } \\
\hline Parameter & Apr & May & Jun & Jul & Aug & Sep & Oct & Nov & Dec & Jan \\
\hline T $\left({ }^{\circ} \mathrm{C}\right)$ & 16.7 & 23.7 & 28.5 & 35.8 & 38.4 & 31.7 & 26.2 & 17.3 & 12.2 & 9.1 \\
RH $(\%)$ & $53-67$ & $61-73$ & $62-83$ & $60-74$ & $72-88$ & $67-73$ & $63-71$ & $42-53$ & $38-57$ & $36-62$ \\
WS $\left(\mathrm{m} \mathrm{s}^{-1}\right)$ & 2.8 & 3.1 & 3.3 & 3.1 & 3.6 & 2.9 & 3.1 & 2.6 & 2.7 & 2.5 \\
\hline
\end{tabular}

this research was a modification of OECD standard wastewater ${ }^{22}$ and was prepared prior to the addition of each batch by mixing the following components in tap water: $500 \mathrm{~g} \mathrm{~m}^{-3}$ glucose, 80 $\mathrm{m}^{-3}$ carbamide, $15 \mathrm{~g} \mathrm{~m}^{-3} \mathrm{NaH}_{2} \mathrm{PO}_{4}, 1.5 \mathrm{~g} \mathrm{~m}^{-3} \mathrm{KH}_{2} \mathrm{PO}_{4}, 4 \mathrm{~g} \mathrm{~m}^{-3}$ $\mathrm{CaCl}_{2}$ and $2 \mathrm{~g} \mathrm{~m}^{-3} \mathrm{MgSO}_{4}$ for high COD loading treatment; $200 \mathrm{~g} \mathrm{~m}^{-3}$ glucose, $240 \mathrm{~g} \mathrm{~m}^{-3}$ carbamide, $15 \mathrm{~g} \mathrm{~m}^{-3} \mathrm{NaH}_{2} \mathrm{PO}_{4}$, $1.5 \mathrm{~g} \mathrm{~m}^{-3} \mathrm{KH}_{2} \mathrm{PO}_{4}, 4 \mathrm{~g} \mathrm{~m}^{-3} \mathrm{CaCl}_{2}$ and $2 \mathrm{~g} \mathrm{~m}^{-3} \mathrm{MgSO}_{4}$ for high $\mathrm{N}$ loading treatment. The characteristics of the influent synthetic wastewater were showed in Tables 2 and 3.

Measurement of water quality: During the experimental period, influent and effluent waters in the hybrid VFCWs were sampled and analyzed every two weeks. The COD, TN and TP were analyzed by standard methods ${ }^{23}$. The dissolved oxygen (DO) and temperature were measured using an Orion Dissolved Oxygen Probe (Model 862Aplus, USA). Oxidation-reduction potential (ORP) and $\mathrm{pH}$ were recorded with Orion 250Aplus ORP Field Kit and Portable pH Meter (Model 250Aplus, USA), respectively.

The nutrient removal efficiency was calculated as:

$$
\mathrm{R}=\left(1-\frac{\mathrm{C}_{\mathrm{e}}}{\mathrm{C}_{\mathrm{i}}}\right) \times 100
$$

where $\mathrm{R}$ is the removal efficiency $(\%), \mathrm{C}_{\mathrm{i}}$ and $\mathrm{C}_{\mathrm{e}}$ are the influent and effluent concentrations $\left(\mathrm{mg} \mathrm{L}^{-1}\right)$, respectively. The mean effluent values for every batch sample over each month were used to calculate removal rates of each parameter.

Plant harvesting and nutrient storage: To follow the growth of plants, morphological measurements were carried out at the end of the experiment. The total number of Herba Scirpi Tabernaemontani plants in each wetland was counted. The belowground (roots and rhizomes) and aboveground (leaves and stems) tissues were separated by hand and their dry weights were measured for each. Roots and rhizomes were washed firstly by tap water then by distilled water to remove any adhering sediments. Each sample was cut into small pieces, well-mixed and oven-dried to constant weight at $80^{\circ} \mathrm{C}$ for dry weight. $\mathrm{N}$ contents of the dried plant tissue were determined by the Kjeldahl method, while $\mathrm{P}$ was measured by the molybdateascorbic acid method ${ }^{24}$.

Statistical analyses: All statistical analyses were performed using SPSS software ${ }^{25}$. One-way ANOVA was used to test differences in related parameters of the four types of hybrid CWs under different influent conditions. Two-way ANOVA was used to test difference in effects of loading variation treatments, combinations pattern, seasons and their interaction on treatment performance. Duncan's multiple range tests was used to further assess differences among treatment combinations that were significant in ANOVA.

\section{RESULTS AND DISCUSSION}

Physicochemical factors: Changes in values of the physicochemical factors of $\mathrm{DO}, \mathrm{ORP}, \mathrm{pH}$ and water temperature were showed in Table-3. The results of high COD loading treatments and high $\mathrm{N}$ loading treatments were similar. DO levels in the effluent were significantly lower than that in

TABLE-2

MEAN CONCENTRATIONS \pm SD OF INFLUENT WASTEWATER AND NUTRIENT REMOVAL EFFICIENCIES. VALUES WITH DIFFERENT SUPERSCRIPT LETTERS IN THE SAME ROW ARE SIGNIFICANTLY DIFFERENT AT $p=0.05$ ACCORDING TO DUNCAN'S MULTIPLE RANGE TESTS

\begin{tabular}{|c|c|c|c|c|c|c|}
\hline \multirow{2}{*}{\multicolumn{2}{|c|}{ Parameters }} & \multirow{3}{*}{$\begin{array}{c}\text { Influent }\left(\mathrm{mg} \mathrm{L}^{-1}\right) \\
507.38 \pm 6.94\end{array}$} & \multicolumn{4}{|c|}{ Removal efficiency (\%) } \\
\hline & & & \multirow{2}{*}{$\frac{\text { VUF-VUF }}{83.26^{\mathrm{a}} \pm 6.36}$} & \multirow{2}{*}{$\frac{\text { VDF-VDF }}{85.04^{\mathrm{a}} \pm 5.34}$} & \multirow{2}{*}{$\frac{\text { VUF-VDF }}{91.12^{\mathrm{b}} \pm 5.61}$} & \multirow{2}{*}{$\frac{\text { VDF-VUF }}{95.17^{\mathrm{c}} \pm 2.74}$} \\
\hline & COD & & & & & \\
\hline High organic & $\mathrm{TN}$ & $41.29 \pm 3.07$ & $78.45^{\mathrm{a}} \pm 6.12$ & $79.04^{\mathrm{a}} \pm 5.46$ & $84.22^{b} \pm 4.91$ & $88.37^{\mathrm{c}} \pm 4.63$ \\
\hline & $\mathrm{TP}$ & $5.34 \pm 0.35$ & $82.64^{\mathrm{a}} \pm 5.91$ & $83.57^{\mathrm{a}} \pm 6.27$ & $85.39^{a} \pm 5.95$ & $87.15^{\mathrm{a}} \pm 5.32$ \\
\hline \multirow{3}{*}{ High $\mathrm{N}$ loading } & COD & $207.48 \pm 4.79$ & $80.34^{a} \pm 4.63$ & $82.52^{a} \pm 5.76$ & $90.01^{b} \pm 4.33$ & $94.33^{c} \pm 3.82$ \\
\hline & $\mathrm{TN}$ & $121.37 \pm 3.08$ & $80.32^{a} \pm 4.77$ & $83.26^{\mathrm{a}} \pm 5.18$ & $91.51^{b} \pm 2.70$ & $95.84^{\mathrm{c}} \pm 2.00$ \\
\hline & $\mathrm{TP}$ & $5.27 \pm 0.32$ & $84.19^{a} \pm 2.75$ & $84.61^{\mathrm{a}} \pm 3.73$ & $86.71^{\mathrm{a}} \pm 4.61$ & $88.92^{\mathrm{a}} \pm 2.92$ \\
\hline
\end{tabular}

TABLE-3

MEAN CONCENTRATIONS \pm SD OF PHYSICOCHEMICAL FACTORS. VALUES WITH DIFFERENT SUPERSCRIPT LETTERS IN THE SAME ROW ARE SIGNIFICANTLY DIFFERENT AT $p=0.05$ ACCORDING TO DUNCAN'S MULTIPLE RANGE TESTS

\begin{tabular}{|c|c|c|c|c|c|c|}
\hline \multirow{2}{*}{\multicolumn{2}{|c|}{ Parameters }} & \multirow{2}{*}{ Influent } & \multicolumn{4}{|c|}{ Effluent } \\
\hline & & & VUF-VUF & VDF-VDF & VUF-VDF & VDF-VUF \\
\hline \multirow{4}{*}{$\begin{array}{l}\text { High organic } \\
\text { loading }\end{array}$} & $\mathrm{DO}\left(\mathrm{mg} \mathrm{L}^{-1}\right)$ & $3.59^{a} \pm 1.17$ & $1.53^{b} \pm 0.43$ & $1.64^{b} \pm 0.67$ & $1.72^{b} \pm 0.95$ & $1.73^{b} \pm 0.82$ \\
\hline & ORP (mV) & $53.28^{\mathrm{a}} \pm 1.75$ & $32.44^{\mathrm{b}} \pm 9.47$ & $30.26^{\mathrm{b}} \pm 11.34$ & $33.74^{\mathrm{b}} \pm 14.37$ & $31.47^{\mathrm{b}} \pm 13.12$ \\
\hline & $\mathrm{pH}$ & $7.49^{\mathrm{a}} \pm 0.27$ & $7.31^{c} \pm 0.26$ & $7.37^{\mathrm{c}} \pm 0.45$ & $7.41^{b} \pm 0.18$ & $7.42^{\mathrm{b}} \pm 0.37$ \\
\hline & $\mathrm{T}\left({ }^{\circ} \mathrm{C}\right)$ & $17.1^{\mathrm{a}} \pm 2.7$ & $20.9^{a} \pm 2.8$ & $20.1^{\mathrm{a}} \pm 2.7$ & $21.8^{a} \pm 4.6$ & $21.9^{\mathrm{a}} \pm 2.1$ \\
\hline \multirow{4}{*}{ High $N$ loading } & $\mathrm{DO}\left(\mathrm{mg} \mathrm{L}^{-1}\right)$ & $3.07^{\mathrm{a}} \pm 0.98$ & $1.38^{b} \pm 0.87$ & $1.41^{b} \pm 1.51$ & $1.57^{b} \pm 1.13$ & $1.63^{b} \pm 0.99$ \\
\hline & ORP $(\mathrm{mV})$ & $69.38^{a} \pm 4.13$ & $53.84^{b} \pm 11.09$ & $49.34^{b} \pm 10.44$ & $59.31^{b} \pm 9.43$ & $60.39^{b} \pm 8.35$ \\
\hline & $\mathrm{pH}$ & $7.63^{a} \pm 0.21$ & $7.43^{c} \pm 0.31$ & $7.41^{\mathrm{c}} \pm 0.18$ & $7.51^{b} \pm 0.19$ & $7.49^{b} \pm 0.23$ \\
\hline & $\mathrm{T}\left({ }^{\circ} \mathrm{C}\right)$ & $17.3^{\mathrm{a}} \pm 1.3$ & $21.2^{a} \pm 4.6$ & $21.5^{\mathrm{a}} \pm 3.4$ & $20.2^{a} \pm 3.1$ & $22.9^{a} \pm 5.6$ \\
\hline
\end{tabular}


influent $(p<0.05)$, but no significant differences in effluent for DO were detected among various two-stage combinations CWs $(p>0.05)$. The similar results were obtained in the case of ORP values. Water temperature did not change greatly, the mean temperatures of the influent and effluents of the four kinds of two-stage combinations CWs were not significantly different $(p>0.05)$. The $\mathrm{pH}$ values were significantly lower $(p<0.05)$ in the effluent of all four kings of two-stage combinations CWs compared to the influent. There were no significant differences $(p>0.05)$ between VDF-VDF and VUF-VUF, as well as VUF-VDF and VDF-VUF, but VUF-VDF and VDFVUF were significantly higher $(p<0.05)$ than VDF-VDF and VUF-VUF. The variation of $\mathrm{pH}$ values largely depended on the extent of nitrification in the VFCWs ${ }^{11}$. As can be seen from Table-3, the effluent $\mathrm{pH}$ values were always lower than the influent $\mathrm{pH}$ and below 8 , which is very important for an efficient nitrification. In addition, the ammonium volatilization processes played a negligible role for $\mathrm{TN}$ removal in this research since $\mathrm{pH}$ was always lower than 8 (Table- 3$)^{14}$.

Plant nutrient accumulation: There were no significant differences among the four kinds of two-stage combinations $\mathrm{CWs}$ for plant nutrient accumulation and contribution rate to nutrient removal $(p>0.05)$ (Table-4). The average $\mathrm{N}$ and $\mathrm{P}$ accumulations of plant fractions during the study period were ranged between $1.53 \pm 0.53$ and $1.75 \pm 0.39 \mathrm{~g} \mathrm{~m}^{-2} \mathrm{~d}^{-1}$ and 0.27 \pm 0.11 and $0.45 \pm 0.21 \mathrm{~g} \mathrm{~m}^{-2} \mathrm{~d}^{-1}$, respectively. The average contribution rates to $\mathrm{TN}$ and $\mathrm{TP}$ removal were ranged between $9.98 \pm 3.27,11.32 \pm 1.94,2.29 \pm 0.54$ and $3.59 \pm 0.98 \%$, respectively.

The amounts of phosphorus and nitrogen removed via plant growth in these CWs were negligible compared to comparing to the removal efficiency of TP and TN with biological degradation and adsorption and/or precipitation process (Table$2)$. These phenomena indicated that plant accumulation was not an important removal process for phosphorus and nitrogen. These results were agreed with research of Zhou et al. ${ }^{13}$. In fact, most of nutrient, i.e., phosphorus and nitrogen, were mainly removed by the microorganisms in plant root zones, as well as adsorption and/or precipitation process in the bed substrate of VFCWs ${ }^{4,16,17,26,27}$.

Removal efficiency of nutrient: The removal efficiencies of COD, TN and TP in four kinds of two-stage combinations CWs were represented in Table-2. All kinds of two-stage combinations CWs achieved good nutrient removal effect to treat high-strength wastewater. COD, TN and TP removal efficiency of various two-stage combinations CWs under high COD loading treatments ranged between $83.26 \pm 6.36,95.17 \pm 2.74$, $78.45 \pm 6.12,88.37 \pm 4.63,82.64 \pm 5.91$ and $87.15 \pm 5.32 \%$, respectively. Under high $\mathrm{N}$ loading treatments, $\mathrm{COD}, \mathrm{TN}$ and TP removal efficiency were ranged between $80.34 \pm 4.63$, $94.33 \pm 3.82,80.32 \pm 4.77,95.84 \pm 2.00,84.19 \pm 2.75$ and $88.92 \pm 2.92 \%$, respectively. These results were much better than that in literatures. Hogain ${ }^{3}$ reported that COD removal efficiency was only $89 \%$ in a combination of $\mathrm{VF}$ and $\mathrm{HF}$ hybrid CWs in Ireland with inflow COD loading of $462 \mathrm{mg} \mathrm{L}^{-1}$. Brix et $a l .{ }^{9}$ reported that COD removal efficiency of $78 \%$ with inflow COD loading of $216 \mathrm{mg} \mathrm{L}^{-1}$ and TN removal efficiency of $61 \%$ with inflow TN loading of $72.2 \mathrm{mg} \mathrm{L}^{-1}$ in a combination of HF and VF hybrid CWs in Denmark. These results could be explained by the theory that aerobic-anaerobic environment in two-stage combinations CWs in this research was better than that in conventional combination of $\mathrm{HF}$ and VF hybrid CWs. This aerobic-anaerobic environment was very important for metabolism of microorganisms in root zones that could decontaminate nutrients ${ }^{13}$. The high COD loading treatments and high $\mathrm{N}$ loading treatments represented similar results about nutrients removal under different kinds of twostage combinations CWs.

Removal efficiency of COD: The COD removal efficiency in VDF-VUF was significantly higher $(p<0.05)$ than other kinds of two-stage combinations CWs. There were no significant differences $(p>0.05)$ in removal efficiency of COD between VUF-VUF and VDF-VDF, but VUF-VDF was significantly higher $(p<0.05)$ than VUF-VUF and VDF-VDF (Table-2). These phenomena could be explained by the theory that in two-stage combinations CWs, aerobic processes predominated on the surface of the plant roots in VDF CWs, whereas anaerobic processes took place in VUF CWs. Therefore, VUF-VDF and VDF-VUF CWs were able to establish a special aerobic-anaerobic environment in plant root zones that support the growth of various microorganisms and then indirectly accelerate the removal of COD in wastewater ${ }^{13}$. The aerobic-anaerobic environment was also suitable for the growth of specific tissues (aerenchyma) of plant that supply plant root systems with atmospheric oxygen and permit subsurface roots to act as giant biological filters ${ }^{4}$.

Especially, in the two-stage combinations of CWs with same flow regimes, the COD removal efficiency in the VDFVDF was higher than that in the VUF-VUF CWs although the differences were not significant $(p>0.05)$ (Table-2). This was

TABLE-4

MEAN VALUES \pm SD OF PLANT NUTRIENT ACCUMULATION AND CONTRIBUTION RATE TO NUTRIENT REMOVAL. VALUES WITH DIFFERENT SUPERSCRIPT LETTERS IN THE SAME ROW FOR THE SAME HIGH LOADING INDICATE ARE SIGNIFICANTLY DIFFERENT AT $p<0.05$ ACCORDING TO DUNCAN'S MULTIPLE RANGE TESTS

\begin{tabular}{|c|c|c|c|c|c|}
\hline & \multirow{2}{*}{ Item } & \multicolumn{4}{|c|}{ CWs } \\
\hline & & VUF-VUF & VDF-VDF & VUF-VDF & VDF-VUF \\
\hline \multirow{4}{*}{$\begin{array}{l}\text { High organic } \\
\text { loading }\end{array}$} & N Accumulation $\left(\mathrm{g} \mathrm{m}^{-2} \mathrm{~d}^{-1}\right)$ & $1.64^{\mathrm{a}} \pm 0.27$ & $1.61^{\mathrm{a}} \pm 0.37$ & $1.57^{\mathrm{a}} \pm 0.39$ & $1.63^{\mathrm{a}} \pm 0.41$ \\
\hline & Contribution rate to $\mathrm{TN}$ removal (\%) & $11.15^{\mathrm{a}} \pm 2.35$ & $10.99^{a} \pm 3.94$ & $10.81^{\mathrm{a}} \pm 3.07$ & $10.71^{\mathrm{a}} \pm 2.95$ \\
\hline & P Accumulation $\left(\mathrm{g} \mathrm{m}^{-2} \mathrm{~d}^{-1}\right)$ & $0.29^{\mathrm{a}} \pm 0.09$ & $0.27^{\mathrm{a}} \pm 0.11$ & $0.31^{\mathrm{a}} \pm 0.15$ & $0.35^{\mathrm{a}} \pm 0.18$ \\
\hline & Contribution rate to TP removal $(\%)$ & $2.29^{a} \pm 0.54$ & $2.83^{\mathrm{a}} \pm 0.75$ & $2.98^{\mathrm{a}} \pm 1.31$ & $3.01^{\mathrm{a}} \pm 1.24$ \\
\hline \multirow{4}{*}{ High $\mathrm{N}$ loading } & $\mathrm{N}$ Accumulation $\left(\mathrm{g} \mathrm{m}^{-2} \mathrm{~d}^{-1}\right)$ & $1.73^{\mathrm{a}} \pm 0.31$ & $1.64^{\mathrm{a}} \pm 0.29$ & $1.53^{\mathrm{a}} \pm 0.53$ & $1.75^{\mathrm{a}} \pm 0.39$ \\
\hline & Contribution rate to $\mathrm{TN}$ removal $(\%)$ & $11.32^{\mathrm{a}} \pm 1.94$ & $9.98^{\mathrm{a}} \pm 3.27$ & $10.92^{\mathrm{a}} \pm 3.98$ & $10.89^{\mathrm{a}} \pm 3.37$ \\
\hline & P Accumulation $\left(\mathrm{g} \mathrm{m}^{-2} \mathrm{~d}^{-1}\right)$ & $0.31^{\mathrm{a}} \pm 0.06$ & $0.29^{\mathrm{a}} \pm 0.11$ & $0.43^{\mathrm{a}} \pm 0.31$ & $0.45^{\mathrm{a}} \pm 0.21$ \\
\hline & Contribution rate to TP removal (\%) & $3.41^{\mathrm{a}} \pm 0.25$ & $3.17^{\mathrm{a}} \pm 0.84$ & $3.45^{\mathrm{a}} \pm 1.22$ & $3.59^{\mathrm{a}} \pm 0.98$ \\
\hline
\end{tabular}


because the VDF was able to maintain better aerobic conditions in which the aerobic microorganisms could provide greater capacity for oxidation of organic matter than anaerobic microorganisms ${ }^{13}$. Meanwhile, the COD removal efficiency in VDF-VUF was significantly higher $(p<0.05)$ than that in VUF-VDF (Table-2), although VDF-VUF and VUF-VDF were both characterized by two-stage combinations of CWs with different flow regimes. This was due to the theory that anaerobic environment, which was predominated in the first stage (VUF) of VUF-VDF, would inhibit the reproducing process of aerobic bacteria. Therefore, there were inadequate aerobic bacteria could be found in the second stage (VDF) of VUF-VDF for accelerating the COD removal in wastewater ${ }^{11}$. Well then, the VDF-VUF CWs was the optimum two-stage combinations for COD removal.

Removal efficiency of TN: The removal efficiency of TN in VDF-VUF was significantly higher $(p<0.05)$ than that in the rest of combinations. Furthermore, VUF-VDF was significantly higher $(p<0.05)$ than VUF-VUF and VDF-VDF, but there were no significant differences $(p>0.05)$ between VUFVUF and VDF-VDF (Table-2). These phenomena could be explained by the fact that that VUF-VDF and VDF-VUF CWs were able to achieve simultaneous nitrification denitrification successfully due to VDF could establish an aerobic environment for the growth of nitrifying bacteria and VUF could establish an anaerobic environment for the growth of denitrifying bacteria simultaneously ${ }^{13,28}$. In contrast, in the two-stage combinations of CWs with same flow regimes, VDF-VDF or VUF-VUF cannot achieve significant removal of TN due to inability of the combinations to provide anoxic/anaerobic conditions for nitrification/denitrification. VDF-VDF CWs could successfully remove ammonia-N with nitrifying bacteria in the established aerobic environment, but only limited denitrification occurred in such combination; VUF-VUF CWs provide appropriate conditions for denitrification with established anaerobic environment, but nitrification process was limited ${ }^{18}$.

Furthermore, TN removal efficiency in VDF-VUF was significantly higher $(p<0.05)$ than that in VUF-VDF (Table2), although VDF-VUF and VUF-VDF were both characterized by two-stage combinations of CWs with different flow regimes. This was because the VDF was aerobic first and anaerobic next, whereas VUF was anaerobic first and aerobic next according to their structure (Fig. 1a). Therefore, the VDF-VUF was able to achieve a sequential anaerobic environment which was the combination of the second step of VDF and first step of VUF. This sequential anaerobic environment could provide sufficient conditions for denitrification, while there did not exist sequential anaerobic environment in the VUF-VDF ${ }^{13,19}$.

In fact, the nitrogen removal mechanisms in VFCWs mainly included ammonium volatilization, plant uptake and nitrification/denitrification in theory ${ }^{27,29}$. But ammonium volatilization process could be negligible due to $\mathrm{pH}$ in this research was always lower than 8 (Table- 3$)^{14}$. Furthermore, plant uptake contributed to the TN removal was of little quantitative importance as shown in Table-4. Therefore, nitrification/denitrification was the most important process for TN removal in this research. These results were quite agreed with Zhou et al. ${ }^{13}$.
In addition, the $\mathrm{DO}$ concentrations were generally higher in the effluent from the VDF-VUF CWs than the other CWs under high organic/N loading treatments (Table-3). This also suggested that nitrification/denitrification coupling was improved in VDF-VUF CWs, while the VUF-VDF, VDF-VDF and VUF-VUF CWs was incapable of achieving preferable TN removal because of the inability of these three kinds of two-stage combinations CWs to provide appropriate anoxic/ anaerobic conditions for nitrification/denitrification ${ }^{19,28}$. Thus, the optimum two-stage combination for TN removal was VDFVUF CWs.

Removal efficiency of TP: Multiple comparisons detected slightly higher TP removal efficiency in the VDF-VUF than other combinations. But no significant difference $(p>0.05)$ was observed among four kinds of two-stage combinations (Table-2). These results were agreed with Zhou et al. ${ }^{13}$. These phenomena could be explained by the theory that TP was mainly removed by the CWs bed substrate in this research. Wastewater was introduced intermittently and then the removal efficiency may not be significant differences among four kinds of two-stage combinations CWs due to oxygenation of the bed of CWs caused desorption and subsequent release of phosphorus. So the effect of the biological transformations of polyphosphate-accumulating organisms was weakened. In fact, TP removal was mainly governed by physical precipitation and chemical adsorption process in the bed medium of gravel and slag particles in this study ${ }^{15-17,30}$.

However, the VDF-VUF showed the highest removal efficiency due to its special sequential aerobic/anaerobic environment. The VDF was aerobic first and anaerobic next, whereas VUF was anaerobic first and aerobic next (Fig. 1a). Therefore, the VDF-VUF was able to achieve a sequential anaerobic environment (the combination of the second step of VDF and first step of VUF) after aerobic environment (the second step of VDF). Although the TP removal was mainly depended on physical precipitation and chemical adsorption process of the bed medium, this sequential anaerobic environment could provide relatively appropriate conditions for the biological transformations of polyphosphate-accumulating organisms in the VUF-VDF to some degrees. The longer the anaerobic environment was, the more the phosphorus could be released by polyphosphate-accumulating organisms and the more phosphorus could be absorbed in the subsequent aerobic environment ${ }^{16,17}$. So, the biological phosphorus removal process was enhanced in some degree ${ }^{15-17,30}$. Consequently, the optimum two-stage combination for TP removal was VDFVUF CWs.

Time course of COD removal: The COD removal efficiency in the VUF-VDF and VDF-VUF CWs showed a similarly higher trend than that in the VUF-VUF and VDFVDF under high organic/N loading treatments (Fig. 2). The VDF-VUF CWs achieved the highest COD removal efficiency all through the time course of experimental period. These were because the special aerobic-anaerobic environment in the plant root zones of VDF-VUF CWs were able to support the growth of various microorganisms, which associations with plant roots in VFCWs could be key factors for COD removal ${ }^{4}$. 


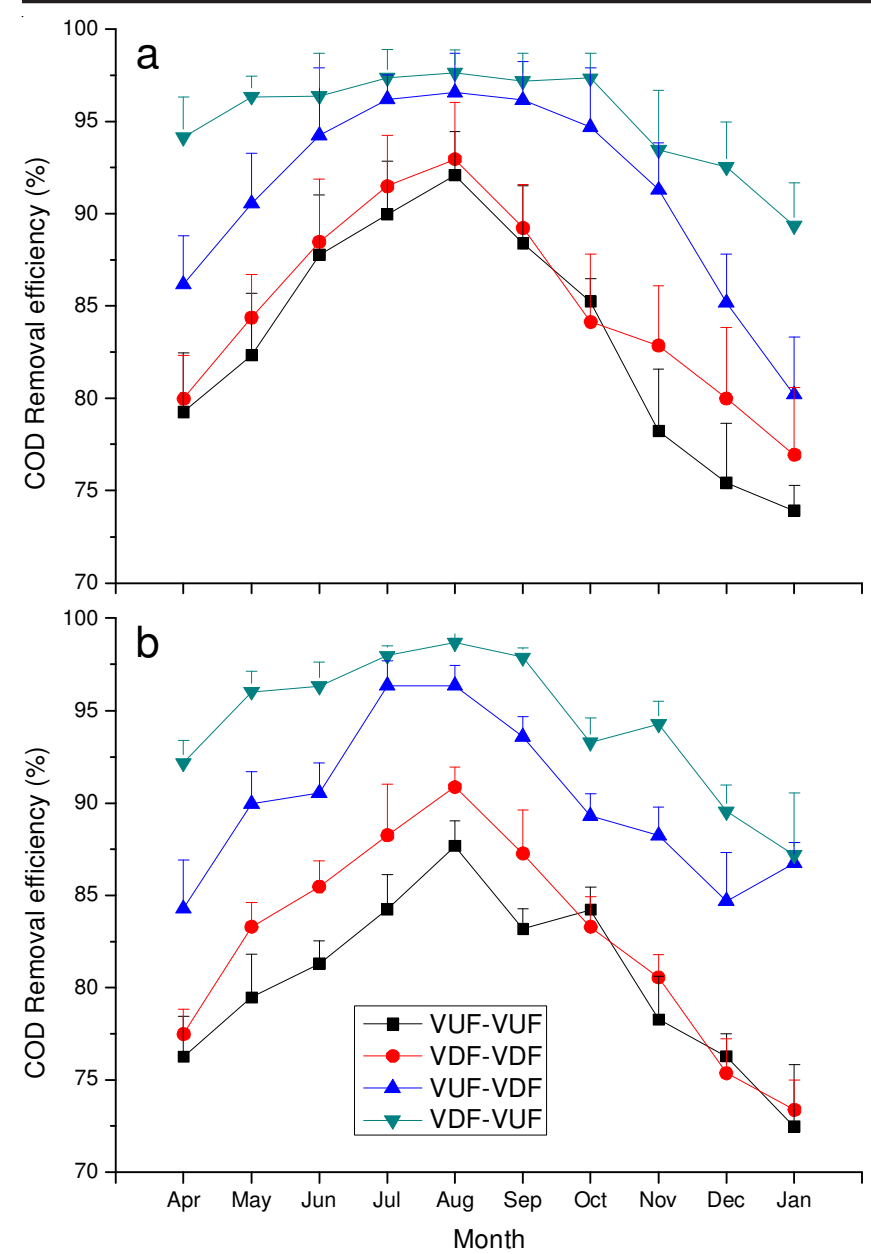

Fig. 2. Time course of COD removal efficiency: (a) high organic loading treatment; (b) high $\mathrm{N}$ loading treatment

The VDF-VUF CWs under high organic loading treatments maintained relatively higher COD removal efficiency during the May to October (Fig. 2a). This result could be attributed to the theory that relatively higher temperatures in the time course of May to October (Table-1) benefit plant growth and microbial reproduction in the plant roots ${ }^{13}$. In addition, high organic loading treatments could produce high COD removal effect due to the high organic environment was appropriate for the organic removal process of microorganisms in plant root zones ${ }^{19}$.

While the VUF-VDF, VUF-VUF and VDF-VDF under high organic loading treatments and all CWs under high $\mathrm{N}$ loading treatments showed the same variation trend (Fig. 2).
The COD removal efficiencies decreased in autumn (September to November) and winter (December to January) after increased in spring (April to May) and summer (June to August). These results were agreed with the variation of environmental temperature (Table-1), suggested that the month of higher temperature achieved the higher COD removal efficiency. The highest COD removal efficiencies of four kinds of two-stage combinations CWs were all achieved in August. This phenomenon was attributed to the theory that relatively higher temperatures in late summer (July and August) and early autumn (September) were benefit for plant growth and microbial reproduction ${ }^{31-33}$. Furthermore, aquatic plants, such as Herba Scirpi Tabernaemontani in this research, had specific tissues (aerenchyma) that supply root systems with atmospheric oxygen and permit subsurface roots to act as giant biological filters. In fact, the microbial associations with plant roots in VFCWs could be key factors for COD removal ${ }^{13}$.

Thus, the COD removal efficiencies under high organic/ $\mathrm{N}$ loading treatments were only significantly affected $(p<0.05)$ by season, system variation and the combined effect of season and system variation (Table-5). Under high organic/N loading treatments, the relatively higher removal efficiency of COD was obtained in late summer and early autumn and the highest value was obtained in August with VDF-VUF CWs.

Time course of TN removal: The VUF-VDF and VDFVUF CWs showed a similarly higher TN removal efficiency than the VUF-VUF and VDF-VDF under high organic/N loading treatments (Fig. 3). The VDF-VUF CWs had the highest TN removal efficiency for the entire research period. These were because the VDF-VUF could achieve simultaneous nitrification denitrification successfully. It supplied a sequential anaerobic environment which was able to provide sufficient conditions for denitrification ${ }^{11}$. In addition, the DO was generally higher in the effluent from the VDF-VUF CWs than the others (Table-3), also indicating that the nitrification/denitrification coupling may be improved in this two-stage combinations $\mathrm{CWs}^{19,28}$.

The VDF-VUF CWs under high $\mathrm{N}$ loading treatments maintained relatively higher TN removal efficiency during the May to November (Fig. 3b). It was agreed with COD removal efficiencies of VDF-VUF CWs under high organic loading treatments in Fig. 2a. These results were attributed to the theory that the adequate organic carbon leads to high TN removal and the denitrification process largely depends on the amount of available organic carbon ${ }^{13}$. Furthermore, relatively higher

\begin{tabular}{|c|c|c|c|}
\hline \multicolumn{4}{|c|}{$\begin{array}{l}\text { TABLE- } 5 \\
\text { ED EFFECTS OF FACTORS FOR EACH PARAMETER UNDER } \\
\text { ASED ON ANALYSIS OF VARIANCE. LOADING VARIATION: } \\
\text { GH N LOADING TREATMENT; SYSTEM VARIATION: VUF-VUF, } \\
\text { ASON: FROM APRIL TO JANUARY; }{ }^{*} p<0.05,{ }^{* *} p<0.01\end{array}$} \\
\hline \multirow{2}{*}{ Factors } & \multicolumn{3}{|c|}{ Nutrient removal efficiency $(\%)$} \\
\hline & COD & $\mathrm{TN}$ & TP \\
\hline Loading variation & 0.162 & 0.175 & 0.181 \\
\hline Season & $<0.0001 * *$ & $0.021 *$ & 0.059 \\
\hline System variation & $0.045^{*}$ & $0.034 *$ & 0.618 \\
\hline Loading variation $\times$ Season & 0.059 & 0.061 & 0.073 \\
\hline System variation $\times$ Season & $0.018^{*}$ & $0.023^{*}$ & 0.117 \\
\hline Loading variation $\times$ System variation & 0.124 & 0.136 & 0.602 \\
\hline System variation $\times$ Loading variation $\times$ Season & 0.112 & 0.235 & 0.374 \\
\hline
\end{tabular}




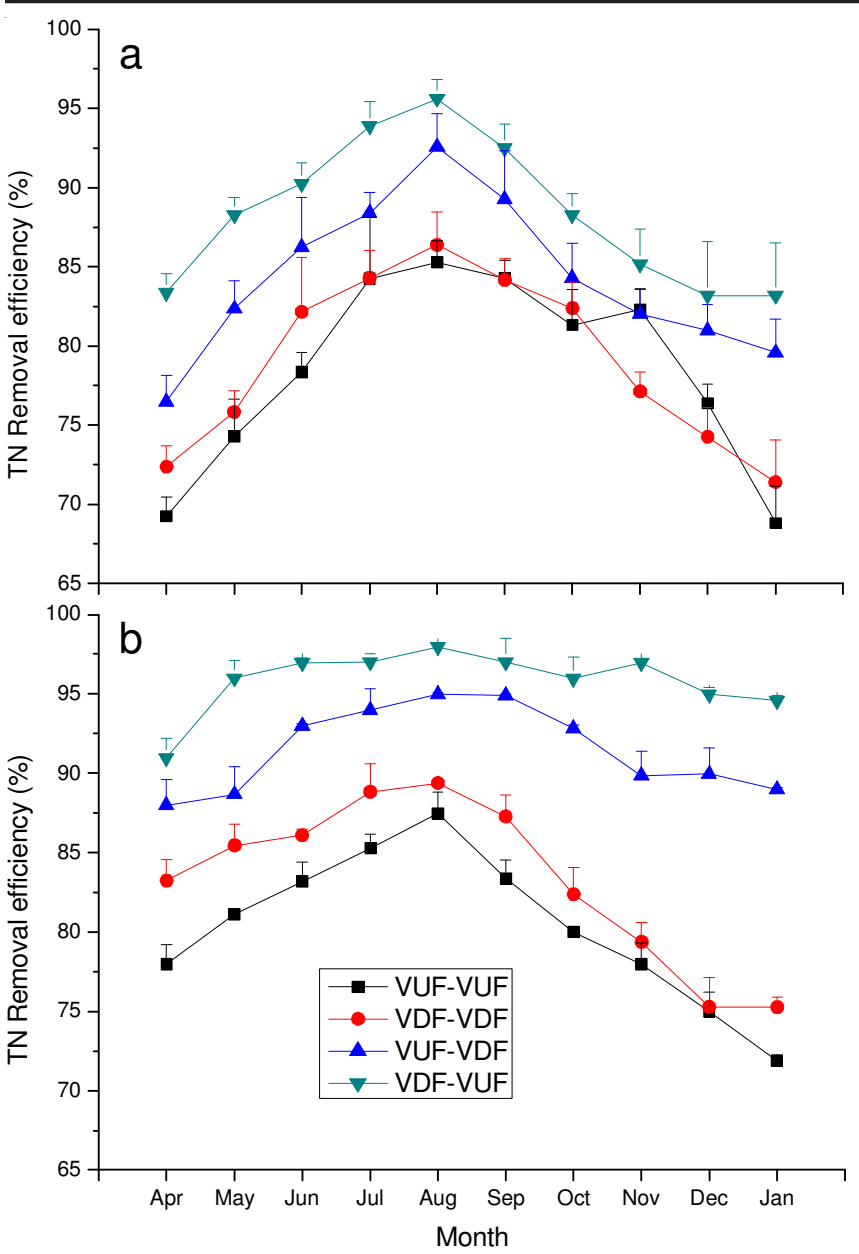

Fig. 3. Time course of TN removal efficiency: (a) high organic loading treatment; (b) high $\mathrm{N}$ loading treatment

temperatures in the time course of May to November (Table-1) benefit plant root systems forming specific tissues (aerenchyma) that support the growth of nitrifying and denitrifying bacteria simultaneously in the aerobic-anaerobic environment (formed by VDF and VUF). In fact, the higher temperature was contributed to the activity of denitrifying and nitrifying bacteria $^{8,12,34}$.

Whereas the VUF-VDF, VUF-VUF and VDF-VDF under high $\mathrm{N}$ loading treatments and all CWs under high organic loading treatments showed the similar fluctuant TN removal efficiencies (Fig. 3). The removal efficiencies of TN decreased in autumn (September to November) and winter (December to January) after increased in spring (April to May) and summer (June to August). These trends were well agreed with the environmental temperature variation (Table-1), indicated that the seasons of higher temperature (late summer and early autumn) achieved the higher TN removal efficiency. This was agreed with the results of Li et al. ${ }^{28}$. Moreover, the highest removal efficiency of TN for all kinds of two-stage combinations CWs was achieved in August. These phenomena were due to the fact that season variation had a significant effect on TN removal (Table-5). Werker et al. ${ }^{34}$ reported the same result which showed that nitrification was strongly temperaturedependent. In this research, the seasons of higher temperature (July and August in late summer and September in early autumn) (Table-1) were conducive to aquatic plants growth, which specific tissues (Aerenchyma) could make plant root systems to become a favorable aerobic-anaerobic environment. Then, simultaneous nitrification denitrification process was able to conduct successfully ${ }^{19,28}$. In addition, the higher temperature was also benefit to the activity of denitrifying and nitrifying bacteria ${ }^{8,12,34}$.

Consequently, the TN removal efficiencies under high organic/N loading treatments were only significantly affected $(p<0.05)$ by season, system variation and the combined effect of season and system variation (Table-5). Under high organic/N loading treatments, the relatively higher $\mathrm{TN}$ removal efficiency was achieved in late summer (July and August) and early autumn (September) and the highest removal efficiency was obtained in August with VDF-VUF CWs.

Time course of TP removal: There were little differences among the TP removal efficiencies of four kinds of two-stage combinations under the high organic/ $\mathrm{N}$ loading treatments during the experimental period (Fig. 4). This was agreed with the results of Pant et al. ${ }^{15}$. This phenomenon could be explained by the fact that the TP removal process was mainly governed by the physical precipitation and chemical adsorption process in the bed medium of gravel and slag particles in this study, rather than the biological transformations of polyphosphateaccumulating organisms ${ }^{15-17,30}$. So the four kinds of two-stage combinations, which equipped with the same bed medium of gravel and slag particles, deservedly demonstrated TP removal effects with little differences.
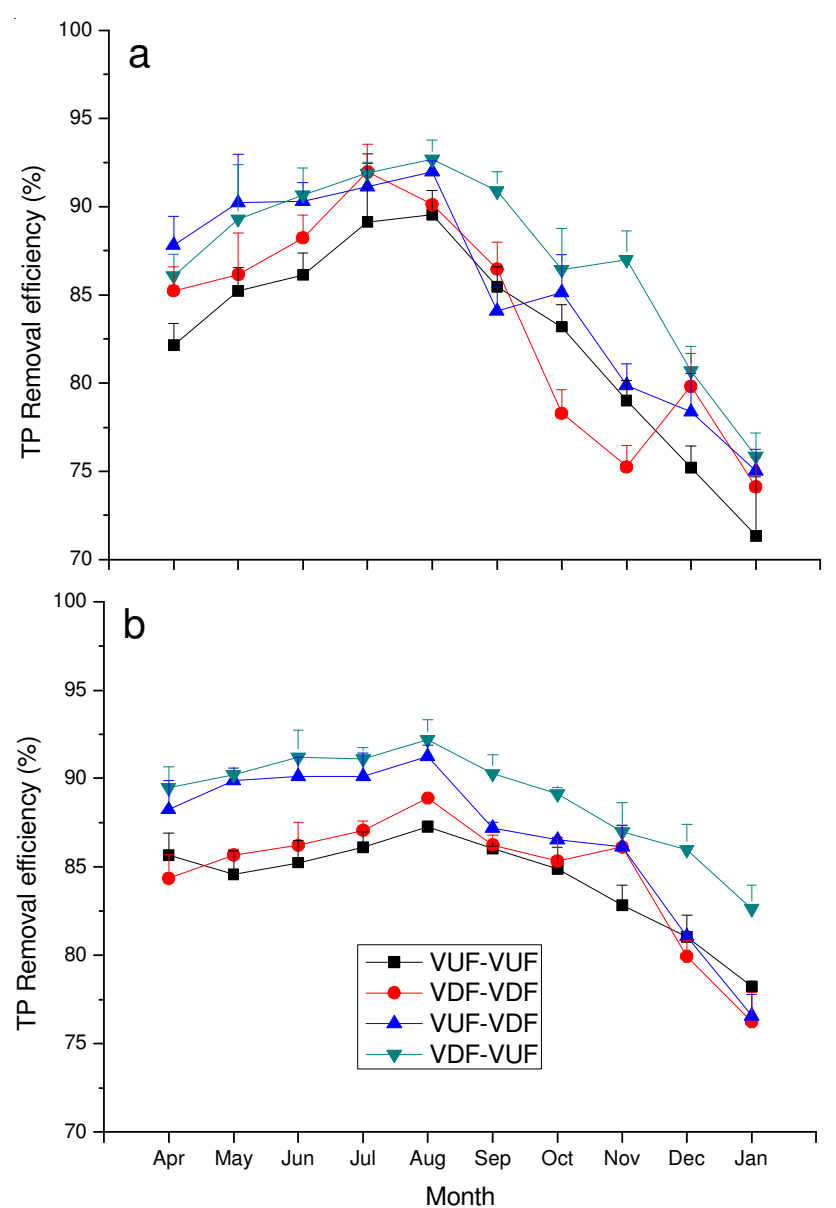

Fig. 4. Time course of TP removal efficiency: (a) high organic loading treatment; (b) high N loading treatment 
But the VDF-VUFCWs still achieved the highest TP removal efficiencies all through the time course of experimental period, which was agreed with the results of COD and TN removal. This could be explained by the fact that although TP removal process was mainly governed by the physical precipitation and chemical adsorption rather than biological transformations, the sequential anaerobic environment, which was the characteristic of VDF-VUF CWs, was able to enhance biological phosphorus removal process in some degree with the help polyphosphate-accumulating organisms ${ }^{15,30}$.

All kinds of two-stage combinations CWs under high organic/N loading treatments demonstrated the similar variation trend (Fig. 4). The TP removal efficiencies were maintained the higher value in the first five months (April to August) and then decreased quickly (September to January). The highest removal efficiencies of TP of four kinds of two-stage combinations CWs were all achieved in August. These results were not agreed with the variation trends of environmental temperature in Table-1, suggested that the removal efficiency of TP was not affected by the season variation (Table-5). Li et al. ${ }^{28}$ reported the same results, which suggested that the phosphate removal was less sensitive to temperature. These phenomena were rational since TP removal was mainly depended on physical precipitation and chemical adsorption process in the bed medium of gravel and slag particles, rather than biological transformations of polyphosphate-accumulating organisms in VFCW s ${ }^{15-17,28,30}$. Furthermore, the fact that TP removal decreased with time after the middle of experiment period was due to the saturation of the sorption site ${ }^{14}$. Weber et al ${ }^{26}$ reported the same results in upgrading CWs with steel slag filters. The adsorption and/or precipitation process of phosphorus by substrate of gravel and slag particles in CWs was a finite process and once the adsorption sites in such CWs became saturated, the phosphorus removal efficiency decreased $^{20,21}$.

The removal efficiencies of total phosphorus under high organic/N loading treatments were not significantly affected $(p>0.05)$ by any factors (Table-5). Under high organic/N loading treatments, the highest TP removal efficiency was achieved in the middle of experiment period (August) with VDF-VUF CWs.

\section{Conclusion}

Four kinds of two-stage combinations CWs (VUF-VUF, VDF-VDF, VUF-VDF and VDF-VUF) showed high nutrient removal efficiencies under high organic/N loading treatments. The control of anaerobic and aerobic processes in two-stage combinations CWs were very important for efficient nutrient removal and the optimum two-stage combination was VDFVUF CWs. Furthermore, the relatively higher nutrient removal efficiency was achieved in late summer (July and August) and early autumn (September) and the highest value was obtained in August during the experiment period. Moreover, COD and $\mathrm{TN}$ removal efficiencies under high organic/N loading treatments were only significantly affected $(p<0.05)$ by season, system variation and the combined effect of season and system variation, while the TP removal efficiencies were not significantly affected $(p>0.05)$ by any factors (Table-5).

\section{ACKNOWLEDGEMENTS}

This study was sponsored by the Beijing Green Future Environment Foundation, the Natural Science Foundation (Project No. 10475040) and the Open Fund from the Shandong Provincial Key Laboratory of Water and Soil Conservation \& Environmental Protection (Grant No. stkf201203).

\section{REFERENCES}

1. Y.X. Li, J.H. Ma, Z.F. Yang and I.C. Lou, Desal. Water Treat., 32, 291 (2011).

2. C.R. Yates and S.O. Prasher, Ecol. Eng., 35, 1693 (2009).

3. S.O. Hogain, Water Sci. Technol., 48, 119 (2003).

4. U. Stottmeister, A. Wiessner, P. Kuschk, U. Kappelmeyer, M. Kappstner, O. Bederski, R.A. Muller and H. Moormann, Biotechnol. Adv., 22, 93 (2003).

5. J. Vymazal, Desal. Water Treat., 4, 40 (2009).

6. A. Albuzio, C. Lubian, R. Parolin, R. Balsamo, I. Camerin and P. Valerio, Desal. Water Treat., 1, 232 (2009).

7. F.J. Diaz, A.T. O'Geena and R.A. Dahlgren, Agric. Water Manage., 104, 171 (2012).

8. S.Q. Wu, J.J. Chang, Y.R. Dai, Z.B. Wu and W. Liang, Desal. Water Treat., 48, 302 (2012).

9. H. Brix, C. Arias and N.H. Johansen, Wetlands: Nutrients, Metals and Mass Cycling, J. Vymazal, Leiden, pp. 237-258 (2003).

10. E. Llorens, J. Puigagut and J. García, Desal. Water Treat., 4, 54 (2009).

11. J. Vymazal and L. Kropfelova, Ecol. Eng., 37, 90 (2011).

12. N. Park, J.W. Lee, K.M. Chon, H.J. Kang and J.W. Cho, Desal. Water Treat., 1, 172 (2009).

13. Y. Zhou, Z.M. Chen, B. Chen, J.B. Zhou, Z. Li, X.R. Xi, C. Lin and G.Q. Chen, Commun. Nonlinear Sci., 13, 1986 (2008).

14. A. Ugurlu and A. Yalcuk, Bioresource Technol., 100, 2521 (2009).

15. H.K. Pant, K.R. Reddy and E. Lemon, Ecol. Eng., 17, 345 (2001).

16. J.Y. Choi, M.C. Maniquiz, B. Lee, S Jeong and L.H. Kim, Desal. Water Treat., 38, 285 (2012).

17. S.C. Ayaz, O. Aktas, N. Findik and L. Akc, Desal. Water Treat., 37, 152 (2012).

18. N. Farahbakhshazad and G.M. Morrison, Environ. Technol., 21, 217 (2000).

19. G. Langergraber, K. Leroch, A. Pressl, K. Sleytr, R. Rohrhofer and R. Haberl, Desalination, 24, 5 (2009).

20. Y.P. Chen, H.B. Guerra, K.S. Min and Y.C. Kim, Desal. Water Treat., 38, 349 (2012).

21. C.A. Prochaska and A.I. Zouboulis, Ecol. Eng., 26, 293 (2006).

22. Guidelines for Testing of Chemicals Simulation Test-Aerobic Sewage Treatment. Technical Report, Organisation for Economic Co-operation and Development (OECD), 1996, OECD, Paris, pp. 3/52-3/83 (1996).

23. Standard Methods for The Examination of Water and Wastewater, APHA-AWWA-WPCF, American Public Health Association, Washington, DC, pp. 4/100-4/246 (1995).

24. Soil Physics and Chemistry Analysis, Institute of Soil Science, Chinese Academy of Sciences, Shanghai Science and Technology Publishing Company, Shanghai, pp. 2/146-5/132 (1978).

25. Analytical Software, SPSS, 2003, SPSS Inc., Chicago, pp. 2/14-2/97 (2003).

26. D. Weber, E. Drizo Twohig, S. Bird and D. Ross, Water Sci. Technol., 56, 135 (2007).

27. S.Y. Lee, M.C. Maniquiz, J.Y. Choi, J.H. Kang, S. Jeong and L.H. Kim, Desal. Water Treat., 48, 9 (2012).

28. L.F. Li, Y.H. Li, D.K. Biswas, Y.G. Nian and G.M. Jiang, Bioresour. Technol., 99, 1656 (2008).

29. J.M. Newman, J.C. Clausen and J.A. Neafsey, Ecol. Eng., 14, 81 (2000).

30. A. Drizo, J. Cummings, D. Weber, E. Twohig, G. Druschel and B. Bourke, Environ. Sci. Technol., 42, 6191 (2008).

31. M.Y. Xing, X.W. Li and J. Yang, Afr. J. Biotechnol., 9, 7513 (2010).

32. C. Li, B. Zhang, J. Zhang, H.M. Wu, H.J. Xie, J.T. Xu and P.Y. Qi, Desal. Water Treat., 32, 271 (2011).

33. J.B. Gormea, M.C. Maniquiza, S.Y. Lee and L.H. Kim, Desal. Water Treat., 45, 136 (2012).

34. A.G. Werker, J.M. Dougherty, J.L. McHenry and W.A. Van Loon, Ecol. Eng., 19, 1 (2002). 